\title{
ESTUDIOS
}

\section{Alberdi y Leroux: la originalidad de la generación argentina de $1837^{*}$}

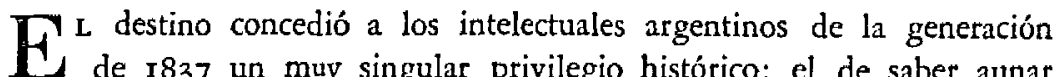
la dialéctica y el coraje, la inteligencia y la acción. Aquellos hijos del siglo fueron cabezas valientes, dándole a la expresión de Larra un nuevo rigor: porque en ellos la densidad ideológica es punto de arranque, fuente de brío. Todos sabemos que en los países de lengua castellana los intelectuales han solido participar en la política más que en otras zonas del planeta: pero es también manifiesto que con harta frecuencia han fracasado por carencia de arrestos para la acción concreta - carencia normal, diríase, en el caso de un intelectual- o por escasez de ideas: escasez más bien sorprendente en quienes se titulan profesionales de la ideación. De ahí también que resalten tanto los hombres del r837 argentino: porque quizás sean ellos los intelectuales con más ideas en el mundo coetáneo suyo de lengua castellana. Esta singularidad histórica de la generación argentina de 1837 se debe ante todo a una conjunción extraordinaria de hombres e ideas: la del pensamiento europeo de la espléndida década r828-1838 con un grupo de argentinos notablemente dotados para el trabajo intelectual. Los hombres del ' 37 argentino eran, como se dice habitualmente de los poetas, intelectuales por la gracia de Dios: pero no basta ser intelectual de nacimiento para llegar a serlo verdaderamente. El intelectual, como el poeta (como decia Federico

* Trabajo leído en New York, el 28 de diciembre de 1964, en la reunión anual de la sección Spanisb 6 (Literatura hispanoamericana desde los origenes hasta 1900) de la Modern Language Association. 
García Lorca), ha de serlo también por la gracia del trabajo, por la cotidianeidad del estudio. $Y$ los argentinos de 1837 fueron, justamente, grandes trabajadores, constantes hombres de estudio. En contraste, por ejemplo, con el héroe epónimo de su generación española, Larra (tan admirado por ellos), que lloraba románticamente el no poder ser Lerminier-"Escribir ... como Hugo y Lerminier es escribir" - "Figarillo" (el argentino Alberdi) se entregaba no menos románticamente al estudio de las obras de aquel filósofo del derecho. Por eso contaron los argentinos de 1837 con tantos recursos intelectuales: operaba en ellos una fuerte voluntad de asimilación de las nuevas y abundantes ideas transatlánticas, única en su intensidad y en su persistencia en el mundo de lengua castellana de su tiempo.

Recordemos los dos textos que relatan el encuentro de hombres e ideas, la conjunción de magnitud casi astrológica de libros y circunstancias. El primero (ateniéndonos a la cronologia de lo relatado y no a la fecha de redacción del texto) es del historiador más importante de aquella genetación, Vicente Fidel López. En su "autobiografia" (pu. blicada en 1896 en la revista de Buenos Aires La Biblioteca, I, Pp. 325355) refiere cómo hacia $I 832$ un muchacho del grupo estudiantil de Buenos Aires, Santiago Viola, hijo único de viuda rica "empleó unos veinte o veinticinco mil francos de fortuna en mandar venir todos los libros de fama corriente en Paris, franceses, italianos, alemanes traducidos, la Revista de París y la Británica completas, con subscripción subsiguiente". Viola adornó además su biblioteca "con un número considerable de retratos litografiados de los autores en boga": y alli acudieron, "al incentivo de aquellas novedades", un número considerable de jóvenes. Algunos de éstos decidieron más tarde, aprovechando la relativa "benignidad" del gobierno del general Balcarce, organizar una "Aso. ciación de estudios históricos y sociales". Esta disposición anímica de los jóvenes argentinos de la década 1830-1840 quedó maravillosamente recogida por Sarmiento en el segundo texto antes aludido. Tras hacerse la pregunta "¿Cómo se forman las ideas?" escribía en sus Recuerdos de provincia (Obras del D. F. Sarmiento, III, Santiago de Chile, I885, Pp. I66-I 67$)$ :

En 1838 fue a San Juan mi malogrado amigo Manuel Quiroga Rosas, con su espíritu mal preparado aún, lleno de fe $y$ de entu. siasmo en las nuevas ideas que agitaban el mundo literario de Francia, y poseedor de una escogida biblioteca de autores modernos. Villemain y Schlegel, en literatura; Jouffroy, Lerminier, Guizot, 
Cousin en filosofía e historia; Tocqueville, Pedro Leroux, en democracia; la Revista Enciclopédica como síntesis de todas las doc. trinas.

Añade Sarmiento, ofreciéndonos la imagen precisa de la conjunción de ideas y hombres en un extremo del mundo euroamericano de 1838.1840 : "Durante dos años consecutivos prestaron estos libros materia de apa. sionada discusión por las noches en una tertulia en la que discutíamos las nuevas doctrinas, las resistiamos, las atacábamos, concluyendo al fin por quedar más o menos conquistados por ellas". Tengamos presente que Sarmiento se hallaba entonces en su villa natal, en la en un principio llamada San Juan de la Frontera: y es muy probable que los libros y revistas de París afectaron más intensamente y profundamente al grupo sanjuanino que a sus lectores europeos. Porque, sin duda, un libro leído en el lugar "central" de su nacimiento - en un París, digamos, donde ese libro está sustentado y es negado simultáneamente por otros librosno puede producir el mismo impacto emocional e intelectual que en la zona periférica de una cultura: esto es, la intensidad de la lectura tiene seguramente mucho que ver con el aislamiento del lector, con la distancia al centro. Don Quijote en Madrid es impensable: por eso sugiero que la avidez con que fueron leídos los libros mencionados en San Juan -una avidez que Sarmiento equipara a la del sediento- fue en gran parte efecto de la distancia geográfica. Mas esa avidez no fue solamente un rasgo provinciano.

Alberdi diría más tarde -expresando muy acertadamente el espí. ritu de la generación de 1837 - que el mundo no suele ocuparse de provincias: y es manifiesto que en la avidez lectora de Sarmiento y sus amigos actuaba también un deseo de salvar las distancias, una patente voluntad de unisonancia intelectual con los europeos de su misma generación: voluntad también operante en los jóvenes de Buenos Aires que al agruparse en una asociación de estudios aspiraban a emular los trabajos de "la nueva escuela francesa", según recordaba Vicente F. López. No olvidemos, por otra parte, que el entusiasmo de los compañeros de éste $\mathrm{y}$ el de los amigos de Sarmiento ante nombres y textos trasatlánticos era en gran medida un reflejo de la actitud de los jóvenes europeos de 1830: en París, en particular, el entusiasmo de los estudiantes - recuérdese que muchos de los pensadores más importantes de esa nueva Europa eran profesores universitarios- fue quizás único en toda la his. toria intelectual francesa. En ello intervenía muy decisivamente el que los maestros fueran apenas un paco mayores que los alumnos: y asimismo 
cl que entre la universidad y los gobernantes hubiera entonces mani. fiestas afinidades. Se proclamaba exaltadamente entonces que las naciones se gobiernan por la palabra (aspiración y programa de Sarmiento más tarde): y muchos catedráticos serán hombres de acción destacados. En esa Francia de 1830 el intelectual queria ser, pues, el ejecutor tanto como el creador de las ideas. Los libros europeos llegaban así a Buenos Aires acompañados, "nimbados" por la aureola del entusiasmo con que habian sido acogidos en París: los jóvenes argentinos conocian ese entusiasmo y aspiraban a revivirlo. Los retratos litografiados que adornaban la biblioteca de la casa de Santiago Viola son muy reveladores: los muchachos platenses querian también sentir la proximidad de los autores, su presencia en efigie, al leer sus artículos y libros.

Mas los lectores argentinos no eran simplemente consumidores de las nuevas ideologias trasatlánticas. Un distinguido historiador se ha referido no hace mucho a la supuesta vaguedad y disparidad de las ideas de Alberdi, repitiendo quizás implícitamente la actitud de Groussac que veía en los argentinos de 1837 miméticos asimiladores del pensamiento europeo: mas un lector como Alberdi ( $\mathrm{y}$ lo mismo podría decirse de sus compañeros de generación) va por asi decir a lo suyo al leer obras ajenas. La intetpretación aludida de la generación de 1837 no apunta a un he. cho fundamental en la biografia intelectual de aquellos argentinos: son hombres con temprana arquitectura mental y por ello mismo son muy diferentes de los intelectuales meramente consumidores de las últimas novedades galas. Yo diría incluso que son lectores que podriamos calificar genéricamente de "unamunianos": porque en sus lecturas actúa siempre el cernedor de una preocupación "radical". Vamos a dar ahora un ejemplo muy ilustrativo de este proceso de utilización y transformación de las ideas trasatlánticas en Juan Bautista Alberdi.

Recordemos que Alberdi publicó en 1837 su Fragimento preliminar al estudio del derecho, obra inspirada esencialmente por los trabajos de Lerminier. En una de las largas notas al pie - casi ensayos adicionales al texto- se plantea Alberdi la cuestión de la verdadera independencia hispanoamericana: "¿sabemos los americanos -escribe Alberdi-que somos menos independientes de la España que lo que nos figuramos?" Alberdi esboza a continuación una interpretación de la historia de España y de la manera de ser hispánica: y al final de la nota señala en otra nota que sobre el tema puede consultarse "una alta ojeada sintética de Pedro Leroux, inserta en la Revista de ambos mutudos, de $I^{\circ}$ de diciembre de I835". Al seguir el consejo de Alberdi y repasar las páginas de la revista citada observé que no había artículo alguno firmado por Leroux: mas 
una reseña anónima del libro del hispanista francés Louis Viardot (Etudes sur l'bistoire des institutions, de la litterrature, du théatre et des beaux arts en Espagne) era evidentemente el artículo, la "alta ojeada", de Leroux según Alberdi. Me sorprendió la atribución y la supuse simple. mente fruto de las relaciones de Alberdi con algún francés bien enterado o con algún amigo residente en París. Pero volviendo a la Revte des Detux Mondes semanas más tarde reparé en un artículo de Charles Didier, en el número del 15 diciembre de 1835 (o sea el siguiente al del artículo citado por Alberdi), "L'Espagne depuis Ferdinand VII": y en una de sus notas al pie (p. 727) Didier atribuye a Pierre Leroux, con muy marcado elogio, la reseña del libro de Viardot. Señalemos que ese artículo de Didier y su continuación del $I^{\circ}$ de enero de 1836 fueron traducidos por Larra, "con las variaciones que ha creido oportunas": una de éstas fue la supresión de la nota citada de Didier. Es manifiesto, por lo tanto, que aunque Alberdi conociera el folleto de Larra ( $D e 183^{\circ}$ a $183^{6}$ o la España desde Femando VII basta Mendizábal, Repullés, Madrid, $183^{6}$ ) se revela en este ejemplo atentísimo lector de la revista parisina. Hagamos ahora un rápido cotejo de los dos textos $\mathrm{y}$ veamos cómo Alberdi "va a lo suyo" al leer a Leroux.

La tesis de Leroux sobre el desarrollo histórico de España no es particularmente original en su conjunto, si se tienen en cuenta muchos juicios de contemporáneos suyos: España no ha participado en la elaboración del mundo moderno ya que no ha pasado por ninguna de las "revoluciones de la inteligencia", que Leroux resume en la sucesión de "la Escolástica, el Renacimiento, la Reforma, la Filosofía". Así, afirma, en estas "cuatro grandes categorías históricas" no aparece ni un solo nombre español. Leroux busca en consecuencia el factor determinante de esta ausencia española y lo halla en lo que podría denominarse el "acti. vismo" hispánico: España ha sido una nación guerrera durante toda la Edad Media y cuando se ha reposado ha empleado su ocio en cantar sus propias glorias: "lorsqu'elle a quelque répit ... elle se chante elle-même". El tema de estos cantos es su misma vida activa, sus hazañas. Ahi está según Lercux la causa verdadera de la decadencia de España: en șu activismo $\mathrm{y}$ en el subsiguiente ensimismamiento. Por otra parte, Leroux señala que la literatura española posee virtudes artísticas que sin duda proceden del factor histórico señalado: las creaciones literarias hispánicas son más naturales, más espontáneas, más modernas que las del resto de Europa. Esa literatura "est soi plus qu'acune autre" (subrayado de Le. roux). Como resultado lógico de ese fuerte carácter singular Leroux es. tima que la literatura española está particularmente dotada para percibir 
la realidad concreta humana: $y$ de esta capacidad española se desprende que España habia de set la creadora de la novela, forma literaria en esencia "realista". Leroux añade inmediatamente que en España incluso el teatro es realista - lo cual es un grave defecto-e igualmente indica que en un país tan "realista" no puede darse la poesía lírica (que él identifica con el sentimiento de lo infinito). Menos aún, claro está, ha sido posible en la peninsula la meditación filosófica: el activismo español es un obstáculo infranqueable en este caso. En conclusión, para Leroux el balance de la historia y de la creación artística de los españoles es muy patente y limitado: "tout s'y rapporte au roman, ou plutôt tout y est le roman sous des formes diverses". España, en suma, es Cervantes, "à des degrés divers". Lope y Calderón, dice Leroux, son también autores "realistas" y por lo tanto dramaturgos secundarios: sólo se han ocupado de las intrigas de la vida madrileña "et des accidents de la vie réelle".

El balance de Alberdi es más negativo, si cabe, que el de Leroux: mas Alberdi declara que escribe sobre "una nación que amamos". Porque Alberdi (como Echeverria y Sarmiento) se siente dentro de la forma de vida hispánica y con su crítica espera realizar una especie de desespañolización íntima, radical: "Para repudiar la herencia era menester inventariarla". Coincide con Leroux en la observación inicial: (España ausente del mundo moderno) pero acentúa considerablemente el tono negativo: "La España ha tenido siempre horror por el pensamiento". Esta repulsa de la actividad intelectual se debe, como en Leroux, al activismo: "Siempre entregada ... a la conquista, jamás al pensamiento". Pero Alberdi, apoyándose en Leroux, añade aquí una "variación" (para emplear el término de Larra) particularmente acertada en su intuición y en su expresión: "La España no es libre porque no ha usado del sustantivo ser... no se ha ocupado nunca de la naturaleza, del ser de las cosas" (Digamos entre paréntesis, y pidiendo que se nos conceda la venia de un aparte anacrónico: ¿no es Alberdi un antecesor en este texto de mi maestro Américo Castro?) Alberdi explica así su referencia: "Y una nación no es libre sino cuando ha gastado por decirlo así el verbo ser: cuando ha comprendido qué es el hombre, qué es el pueblo, cuál es su misión, su rol, su fin". Alberdi utiliza también la interpretación de la literatura española hecha por Leroux, pero marcando casi únicamente las consecuencias desastrosas del "realismo". Cierto, España ha creado la novela "y el romance (en la acepción gacilicista de "roman") es toda fuerza": pero esta habilidad narrativa es la fuente indudable de incontables males. "Que el observador recorra un momento todas las gradas de nuestra escala social $\rightarrow$ y aquí Alberdi se refiere a la Argentina más que a España: o digamos 
a todos los paises que viven dentro de las modalidades hispánicas-y hallará la palabra universal casi ocupada exclusivamente de contar y con. tar eternamente". Ahi está, según Alberdi, la raiz de muchas dificul. tades de orden político: en primer lugar, la "habitud de contar siempre multiplica el espíritu de chisme, de cizaña, de enredo". Además, la ca. pacidad narrativa excluye casi necesariamente la que Alberdi llama capacidad "constitucional": "la incapacidad de generalizar conduce al individualismo... a la ausencia de todo espíritu público, de toda noción de patria".

Alberdi no es, pues, un simple consumidor, un mero traductor mimético de un texto trasatlántico: la referencia de Leroux al predominio de la intriga en el teatro español y su transformación por Alberdi en un juicio general sobre los pueblos de lengua castellana es un claro ejemplo de cómo en el argentino opera siempre la preocupación "radical" antes aludida. Esta preocupación es el eje central del Fragmento preliminar al estzdio del derecho: un individuo como un pueblo sólo "es civilizado cuando posee la teoría y la fórmula de su vida" (Aquí solicitamos de nuevo la venia del inciso anacrónico: ¿no son estas palabras de Alberdi casi pre-orteguianas?) El país que no cuenta con ellas no es capaz ni siquiera de conocerse a sí mismo: España, por ejemplo - volviendo ahora a la nota "inspirada" por Leroux- "sabe hechos pero no posee la expresión general de estos hechos y sus intimidades lógicas con el orden general de los acontecimientos humanos". He aquí —en ese esfuerzo por establecer la teoría de una forma de vida nacional y por precisar "sus intimidades lógicas" con el proceso general de la historia- la originalidad intelectual de Alberdi y sus compañeros de generación. Lerminier, tan admirado por Alberdi, habia pedido a los jóvenes franceses que emprendieran la formulación de una filosofía nacional: "il est temps de travailler a une philosophie nationale". Esta elaboración de una filosofía era, además, indispensable, según Lerminier, para la acción política: se imponia a la juventud "penser pour mieux agir plus tard". Programa que fue realizado mucho más por la generación argentina de 1837 que por los alumnos y lectores trasatlánticos de Lerminier: sin duda, las circuns. tancias históricas y sociales de la Argentina del medio siglo of recian posibilidades de acción intelectual y política que no se presentaban en el mundo complejo y "rígido" de la Europa ocidental, Pero, como en tantos otros casos semejantes, esas circunstancias podian haber sido desa. provechadas, haber sido vistas como la expresión de un sino arrollador y caótico: mas Alberdi y sus compañeros de generación supieron encontrar las "intimidades lógicas" que explicaban los "hechos" y permitian 
a la larga canalizarlos hacia el desarrollo y fortalecimiento de una sociedad liberal. Podría decirse, sin excesiva parcialidad, que aquellos argentinos cumplieron la misión señalada por Alberdi: "La América practica lo que la Europa piensa". Hemos visto cómo en el caso de un texto de Alberdi la "práctica" de un pensamiento europeo lo enriquece con perspectivas insospechadas por su autor. Añadamos, para concluir, que al "practicar" tan originalmente lo que una espléndida Europa "pensaba", la generación argentina de 1837 of rece al historiador una singularidad final: la apuntada por el sociólogo Raúl Orgaz cuando decía que la som. bra de Alberdi daba un poco de vida periódicamente al desterrado de la fama que es Lerminier. ¿No nos indica acaso este hecho que la nueva historia del mundo euroamericano ha de hacerse desde múltiples perspectivas, tanto desde un central París como desde un San Juan de la Fron. tera?

Harvard University

JuAN MARichal 